\title{
A Critical and Ethical Perspective on Governance and Policies during COVID-19 Pandemic in India
}

\author{
SACHIN KUMAR, Cluster Innovation Centre, University of Delhi, India
}

\begin{abstract}
COVID-19, a pandemic has disrupted the lives of citizens across the globe causing irreparable loss of lives, the collapse of socio-economic systems, leading to extreme levels of unemployment. COVID-19 with close to 4.4 lakh deaths, has caused loss of life, human hardship, and extreme burden on health infrastructure and human resources. It has also caused unprecedented challenging times for the governance systems. Consequently, to contain the situation and save human lives, governments all over the world have exercised several measures including lockdown, social distancing, wearing masks mandatorily, improving health facilities, funding the research for vaccine development, and so on. As the result of these actions and adopted strategies, comparatively, some countries, such as Sri Lanka, New Zealand, and Vietnam, were able to contain the spread of the virus and reduce the human and social and economic losses to the country. On the other hand, countries like India, Brazil, and the United States have been still struggling with the COVID-19 and its wide-ranging socio-economic, political, and psychological implications. This article is an attempt to critically and ethically analyse the responses of the government and public authorities to the COVID-19 pandemic scenario and draws some important lessons from them within the ethical framework. This article also discusses necessary future policy, ethical actions, and decision making.
\end{abstract}

CCS Concepts: • Social and professional topics $\rightarrow$ User characteristics; Geographic characteristics;

Additional Key Words and Phrases: Assessment, COVID-19, ethical, India, insights, policies and decisions, governance

ACM Reference format:

Sachin Kumar. 2022. A Critical and Ethical Perspective on Governance and Policies during COVID-19 Pandemic in India. Digit. Gov: Res. Pract. 3, 1, Article 2 (March 2022), 10 pages.

https://doi.org/10.1145/3501032

\section{INTRODUCTION}

COVID-19, as a pandemic, has disrupted life around the world. COVID-19 transmission started due to international travels from China, initially affecting the countries having more incoming and outgoing movement of citizens. After China, other countries such as Italy, Spain, and Iran were taking centre stage with the horrific incidents of deaths, spiking vases of infections, and the collapse of the overburdened health infrastructure [18]. The WHO, a U.N. organization is responsible for managing public health at the international level. Observing the severity of the situation created by COVID-19 in China, Italy, Spain, Iran, and so on, WHO declared the pandemic, a public health emergency in the initial days of March 2020 [4]. Trend of COVID-19 has been depicted in Figure 1. This made the case for other countries to be vigilant and prepared to handle and control situations through measures as they deem fit. This measure might be based on the experiences of severely affected countries.

The world being a global community, interconnected and dependent, COVID-19 has impacted major countries with different degrees of implications. COVID-19 is a new phenomenon that has surprised the whole

Author's address: S. Kumar, Cluster Innovation Centre, University of Delhi, G C Narang Marg, New Delhi, Delhi, India, 110007; email: officialid.sachin@gmail.com.

Permission to make digital or hard copies of all or part of this work for personal or classroom use is granted without fee provided that copies are not made or distributed for profit or commercial advantage and that copies bear this notice and the full citation on the first page. Copyrights for components of this work owned by others than ACM must be honored. Abstracting with credit is permitted. To copy otherwise, or republish, to post on servers or to redistribute to lists, requires prior specific permission and/or a fee. Request permissions from permissions@acm.org.

(c) 2022 Association for Computing Machinery.

2639-0175/2022/03-ART2 \$15.00

https://doi.org/10.1145/3501032

Digital Government: Research and Practice, Vol. 3, No. 1, Article 2. Publication date: March 2022. 


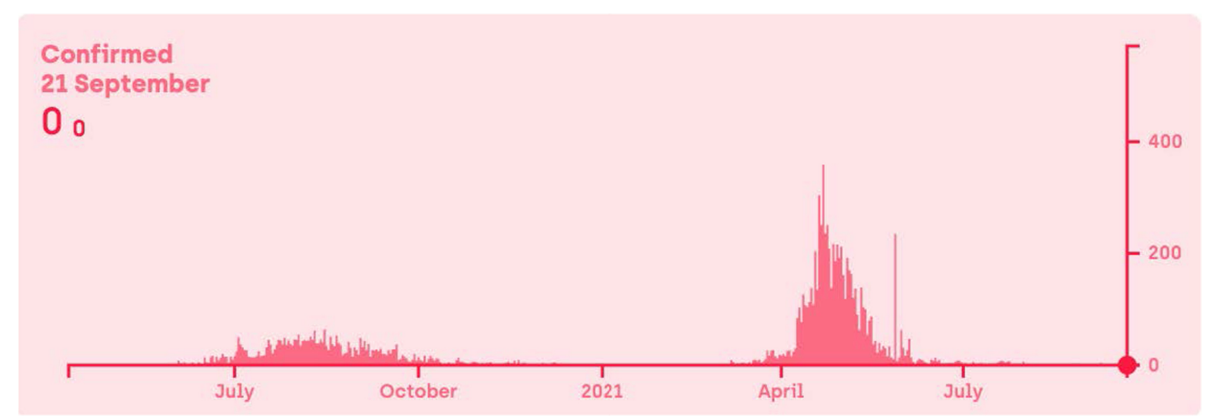

Fig. 1. COVID-19 infection waves in India [3].

world due to its infection rate and spreading patterns and mutations. It has caused loss of human lives, temporary collapse of economic activities in affected countries, high rate of unemployment, socio-economic hardships, overburdened health infrastructure, the threat to the survival of people due to starvation and lack of feed, and other psychological issues such as depression and anxiety. Countries that were inspected initially had no proposer feedback and prior knowledge to handle the COVID-19 situation. This disadvantage made them suffer more from the COVID-19 impact especially on the human lives and health infrastructure. When the scientific community started working on the analyses and hiring the information with WHO, countries geared theme up to control the spread through limited scientific understanding and administrative and governance mechanisms.

Some countries, such as China, Italy, Spain, USA, Iran, Brazil, and India, were affected severely while some other countries, such as New Zealand, Vietnam, Sri Lanka, and the like, were affected in a similar manner but they managed the situation to put them in better position [24, 32, 33]. This can be concluded from the criteria such as COVID-19's death rates and infection rate. In order to counter the infection rate and to save the lives of the citizens, most of the countries adopted some generalised strategies and some customised decisions and policies depending on their own circumstances of the countries. The governance challenges due to COVID-19 in front of the political leadership and administrative machinery included saving human lives, regaining momentum in economic systems, stepping up of health facilities and infrastructure, improving the employment opportunities, supporting the citizens and providing them food and other necessary items, overcoming the psychological fear and traumas of losing loved ones, maintaining law and order, handling unemployment, maintaining social orders, execution of policies, and containment of tyranny of the administration having unprecedented powers in this emergency situation.

India had enough time to prepare itself and execute the necessary steps to prevent herself from the worst implications. Countries like Sri Lanka, Vietnam, New Zeeland and others were also observing the situations and were also in the same category as initial stages of infection rates were similar. They handled the COVID-19 pandemic in a better way, surprising the world and identified themselves as case studies for future pandemics scenarios [13]. However, the Indian administration with its actions and statements did not seem proactive and vigilant. Moreover, it has seemed that they approached the COVID-19 situation in an inconsistent manner without taking the ethics of care into the policy-making, decision-making and policy execution processes. For instance, public authorities were making statements without any substance claiming that the country was well prepared [2]. Administrative staff and leaders were in business as usual and were even participating in large gatherings including election rallies, public events. and the like [14]. Lack of proper and scientific initiatives from a statistical viewpoint, execution of policies in an unscientific manner, and lack of ethical perspectives caused India a great deal in terms of loss of human lives, compaction of the economic capacity, an unprecedented level of the unemployment rate, psychological fears and traumas. Additionally, the public space and information sphere 
of social media platforms such as Facebook, Twitter, YouTube, and so on also became flooded with unscientific and polarised information. National-level media also created the excessive, unscientific, and irrational euphoria of COVID-19 in the mind of the people and government and public officials. There were various governance decisions taken by public authorities that needed ethical and critical scrutiny. Such decisions have been holding state elections, holding rallies without following standard procedures of social distancing and wearing of mask and contradictory statements made by top government officials and executives [14], beating of the vulnerable sections, and suppression of independent and critical voices [25]. This article tries to assess the government decisions and policy making and their immediate impacts, critically and ethically keeping the ethics of care in centrality. Such critical and ethical assessment will help the country and other nations and aware citizens to be more proactive, scientific, and rational in their decisions so that loss of life and economic hardships could be avoided or minimised in future pandemics and effects of future pandemics could be limited and under control.

This article is organised as follows: the first section introduces the COVID-19 scenario. The second section outlines the strategy or series of steps taken by the Indian government and administration. Section 3 assesses critically and ethically the government implemented steps and their implications. Section 4 concludes the article with some directions.

\section{INDIAN COVID-19 STRATEGY AND ITS IMPLEMENTATION}

From March 2020 to November 2020, the Indian government and administration took several policy measures and steps to prevent the spread of the COVID-19 infection and reduce the fatality rate and numbers. One of the important aspects of government decision making has been a sequential approach, not the parallel approach of handling the situation faced due to pandemics. Some of the steps have created confusion due to the overlapping administration activities and domains among states and union governments [15]. Initially, as per the statements, India's administration was observing the COVID-19 developments across the world and preparing the ground for the situation. Political authorities were busy holding large public gatherings and events, rallies in the last phase of February and the initial phase of March 2020. In these phases, a small number of cases were being detected and reported from geographically distant areas of India. Almost all the infection cases had the link to international travels. Suddenly, after March 15, 2020, more cases started coming due to more testing and contact tracing. This sudden increase was given an extremely high dramatised picture by the dominant media through content development and storytelling which lacked any scientific basis and rationality. This seemed to have created panic in the administration and citizens. It seemed that without the availability of real-time scientific data and solid policy and public health statistics, the Indian government also responded swiftly and proposed to impose a severe lockdown. In his address to the nation, the Honourable Prime Minister announced Lockdown at 8:00 PM in night and Lockdown was imposed at 12:00 AM in the morning.

As per the notification of the government, the lockdown was announced to contain the spread of the virus when the total infections were approximately 600 on March 23, 2020 in the whole country [12]. On that day, only some of the states, such as Kerala, Maharashtra, Rajasthan, and Delhi were affected, not the whole country of approximately 130 billion people living in highly diverse geographic and cultural systems. Following the lockdown announcements, the Ministry of Home Affairs (MHA) invoked the provisions of the Epidemic Diseases Act of 1897 and the Disaster Management Act, leading to the temporary closure of all economic activities, commercial establishments, educational establishments, and the like [6]. Since the virus spread from China and through international travel, the Ministry of Civil Aviation (MCA) also halted all aviation activities at the end of March 2020 [22]. State law and order departments and the central government imposed the curfew and lockdown in cities and villages in order to stop the community spread of the virus through excessive use of force and stringent measures [8]. The main proposition behind the lockdown was to break the infection cycle of COVID-19. From the administration point of view, it seemed that the lockdown alone would reduce the cases and contain the spread of COVID-19. 
On the health and infrastructure level, the Ministry of Health and Family Welfare started to report information related to COVID-19 and its mitigation and treatment strategies through press conferences. There was no workable plan from the government side or administration in the public domain. The health infrastructure of the county was not improved and enhanced such as increasing the facility for testing and contact tracing, increase in the availability of bed. It was assumed that lockdown alone would reduce the number of infections of COVID-19 and would break the chain of transmission. The number of testing labs was inadequate compared to the excessive demands of COVID-19 cases owing to the lack of skilled human resources and the lack of infrastructure, lab equipment, and testing kits [5]. Initially, the government attempted to break the chain of the transmission of the infection using lockdown, as observed from their statements and policy directions, but the government failed miserably [26]. There were only 15 labs designated across India led by the National Institute of Virology (NIV), Pune, for virus testing [30]. On March 13th, 52 more labs were designated for testing the COVID-19 [10]. During this time, the Indian government asked for the testing kits from China but the kits were faulty and their accuracy was not acceptable. For instance, China sent 650,000 testing kits to India but their use was discontinued in view of very low accuracy (of just 5.4 per cent). Moreover, on April 16th, 650,000 rapid antibody tests and RNA extraction kits were dispatched from China [21]. On April 21st, the Health Department of West Bengal, one of the states in India, alleged that a large number of testing kits supplied by ICMR-NICED (National Institute of Cholera and Enteric Diseases) were giving inconclusive results [28]. Rajasthan stopped using the rapid testing kits as they had the low accuracy of 5.4 per-cent in comparison to the expected 90 per-cent accuracy [21]. Many times, the Indian government and state government changed their testing limits to report fewer COVID-19 cases.

The adverse impact of the lockdown is reflected in the state of migrant workers. These are the workers and labourers who went to advanced agrarian states such as Punjab, Western Uttar Pradesh, and Haryana, and so on and to industrialised cities for their livelihood and employment. They are below the hand-to-mouth sustenance level and are citizens who have the least social security. The administration's decision to lock down the country without having deliberations about them created havoc in the life of migrant labourers. The administration assured the migrants that they would receive food and shelter but the food and shelter never reached them, forcing them to face death due to starvation or infection. The assurances of the government did not have the ability to stop them as they marched on the highways to reach their native places. On their way back, they were treated inhumanely, totally against the concept of ethics of care,[20]. Health workers also faced evictions from their landlords. Due to the lockdown and the collapse of economic activities, small- and medium-scale industry owners were forced to fire their employees. The government requested the owners without any substantial order or authority. To increase the testing, the National Accreditation Board for Testing and Calibration Laboratories (NABL) accredited private laboratories. Several incidents came to light that private laboratories were charging exuberant fees from patients for the testing. This financial and inhuman harassment spread to a large section of society as the administration did not take up the issues very proactively [16]. Sometimes, socio-economic hardships forced the citizens to take extreme measures. People lost their jobs and the informal sector workers had to live hand to mouth. They were forced to stay where they were without sufficient resources, which forced them to walk on foot or cycle to their native places and villages [9]. The government announced a socio-economic measure to reduce the hardship and financial support to the citizens and various sectors but it was termed as a loan by some economists. The government did not put the money in the hands of the people as initiated by several other countries [27]. The whole episode of the government working and handling the situation was running behind, which could have been avoided keeping in mind the inclusivity and ethics of care in policy with scientific and data-based evidence.

\section{ETHICAL AND CRITICAL ASSESSMENT OF POLICIES AND ACTIONS}

In common parlance, ethics is simply the concern with good and bad actions, obligations, responsibility, and freedom of a person and society at large. It primarily discusses the principles, rules, and methods for a good life. It is essential for any government body to take into account these directive principals before making and 
implementing any policy for the welfare of common people. However, due to contradictory thought processes in the governance system, it is painstaking work for the government to employ these principles in a proper manner. This had a harmful effect on the citizens. It is evident at this point that the Indian strategy has not been successful and that India has one of the largest infections in COVID-19. There are many decisions which remain counterproductive. Assessment from several dimensions is needed to gain the insight into what is to be done and what not. In this situation, it's crucial to develop a caring and reciprocal relationship between the government and the citizens. Citizens should bear their responsibility towards other fellow beings as well as institutions. Similarly, it is not only an obligation but a responsibility of the government authorities to try to comprehend the inner situations, problems, and reasons behind the unsuccessful rate of their policy implementation and execution. Also, they need to work as per requirements of common men situation. This article has ethically and critically discussed various pandemic regulations implemented by the government. The article has also highlighted the reasons behind unsuccessful attempts within the ethics-of-care framework.

\subsection{Dilemmas in Indian Government Policies and Decisions}

Scientifically speaking, in India, COVID-19 cases started rising but not uniformly in all geographic locations [29]. Government officials and top leadership seemed to panic and imposed an almost instant lockdown. Lockdown imposition steps did not give the chance to the people to prepare themselves by storing food-related items and reaching safe places. A severe Lockdown execution started just in 4 hours in the night [23]. A similar type of abrupt decision and giving police and law and order machinery excessive power to execute the harsh but well-intended decisions created humanitarian issues of food scarcity and psychological issues for the migrant labourers and for vulnerable sections of society [23]. On similar lines, Indian governments and their administrators exercised some of decisions which needed to have an ethical and caring approach in declining and execution, keeping human rights in centrality [11]. The impact on a large section of society and on stakeholders such as health workers and immigrants labourers, vulnerable sections such as patients, children, and the elderly people without a proper livelihood-proved that decisions and their execution may be categorised as unscientific and lacking the caring ethics approach needed in decision making [25]. Unscientific comments and opinions of celebrities and political leaders caused the circulation of fake news and misinformation on social media platforms such as Facebook, YouTube, and Twitter, reaching a large section of society [17]. Political parties and their IT cells to disseminate the government programs have caused further confusion in the information sphere in order to counter the negativity towards government decisions and policies by targeting the sections of societies [19]. People took the critical stand against the opening of liquor shops as they might have increased the cases of COVID-19 infections without social distancing and proper mask-wearing [7]. Consequently, it resulted in the spread of COVID-19.

\subsection{Lack of Scientific and Decentralised Approach}

The steps taken by the Indian government and administration to tackle the COVID-19 pandemic has resulted in confused, lethargic decision-making. They seem as taken without scientific and rational planning under uncertain times without anticipation of their consequences. These steps have a list of actions. Starting from not taking the decisions even when the opposition leader and scientific community and experiences of other countries are indicating and terming the COVID-19 a tsunami. Once the COVID-19 displayed its speed and growth as bad as in bad in few other countries such as Italy, Spain, Iran, China, the U.S.A. and U.K., the Indian government felt the heat and suddenly decided to lock down without assessing the country's socio-economic situation, the extent of spread in different geographic area and its aftereffects on human life of citizens and consequences of centralised decision making in a diverse country. Sudden imposition of the lockdown, without active preparation and anticipation of consequent actions, raised socioeconomic issues, human rights issues, and ethical questions. Associated decisions with lockdown impositions were not created from an evidence-based and scientific and 
rational policy framework. This can be assessed from the fact that COVID-19 infections were not uniformly distributed in the whole of India. But the lockdown was uniformly imposed. Lockdown implementation needed regional assessments and localised decisions.

More importantly, India is a very diverse country consisting of 27 states and union territories. These states have their autonomous governance subjects and function by the representative government as per the three lists of constitution [31]. When the lockdown was announced, fewer than eight states had COVID-19-infections. Total COVID-19 cases in the whole country were 600 only. These patients could have been traced vigorously and treated. This needed a focused approach specific to infected geographic areas. Such an unclear view of the situation, without taking evidence-based and scientific policy foundation into consideration, has severe implications on different sections of society, especially weaker sections that are economically and socially poor and vulnerable, such as women, children, and the elderly.

\subsection{Unethical Treatment of Migrants}

There was a lack of the element of ethics of care in providing the services to the immigrants who were working in different states for their livelihood. Some state governments started forceful transportation with inhuman conditions, which resulted in physical and psychological troubles and trials. Scenes from Uttar Pradesh, one of the largest states, witnessed that migrants were forced into mass cleaning and sanitisation like animals and were beaten inhumanely. The government decisions with their consequences seem out of touch with reality and without care of ethics. Data analysis and scientific evidence must have driven the government policy decisions. Decisions needed customization for different trends and patterns COVDI-19 scenarios taking into consideration the diversity of the country and local conditions. India is a highly diverse country from geographical, cultural, religious, secular, and language perspectives [1]. Negligence on the implications of the decisions on several sections of society went against the ethics of care. Apart from migrants, health professionals and healthcare workers faced problems related to lack of equipment, safety kits, and infrastructure. Delay in providing the required medical and health equipments and resources put the decisions of respective state government in question. Brutal and horrifying images of migrant labourers travelling on foot for thousands of kilometres were horrific as the conservative government did not permit transportation and other alternative modes of transportation to reach to the safe place. Migrants thought were that they would be dying here without food and it would be better to reach the safe place. These events completely disregarded the empathy and ethics of care. The government decision proved that they have abandoned the important but vulnerable sections of Indian society that contribute deeply to Indian growth and development.

\subsection{Socio-Economic Hardships}

Millions of people lost their jobs as they were forced to resign or were terminated by their employers. Government heads only made advisory statements and requested the supervisors to not terminate the employees. They did not care to make sustainable moves in order to help the needy. The warnings did not have statutory authority and approvals, leaving these rulings without the force of law. Due to job losses, many people committed suicide. In order to revive the economy and welfare of citizens, the Finance Minister introduced a financial aid programme called "Pradhan Mantri Garib Kalyan Yojana (PMGKY)" to provide relief against COVID-19. The relief package of the PMGKY included 1.7 lakh crore rupees (Dollar, 23.2 billion) for the poor. This included provisions like insurance cover to health workers, 5 kilograms of wheat or rice, and 1-kilogram other food grains. The women account holders were also given the Pradhan Mantri Jan Dhan Yojana (PMJDY) and will get 500 rupees per month from April to June. Critically analysing, this amount was not sufficient for a household. Poor families would be given free gas cylinders for over the next three months when the financial package was announced in 2020. An assessment tells us that this was insufficient to relieve the plight of the people. The economy experts said that government should have given more money to the people so that they could sustain their lives. The 
money circulation in the economy will improve the health of already collapsed economy. Although government did not accept the argument of the handing money or direct cash to the people. Most of the benefits were not direct cash transfers, although other countries implemented direct cash transfers to their citizens. The Finance Minister also implemented the extension and relaxation in payment of taxes such as the taxation and other laws (Relaxation of Certain Provisions) through Ordinance 2020. The ordinance provides certain relaxations, such as the extension of time limits and waivers of penalties, in relation to specified laws. This shows some of the positive aspects of the government functioning, still the executions have been doubtful. Due to the stoppage of economic activities, the government asked for monetary help from citizens and institutions in India and abroad. The government created a new fund called the "PM Care Fund" with the eligibility for a 100 per-cent tax deduction. The trust is chaired by the Prime Minister and includes members from several other ministries such as the Defence Minister, Home Minister, and Finance Minister. Non-residents were also allowed to contribute funds through foreign remittances. But there were many ethical issues raised such as the Fund is not a public authority but can accept the public funds. It violates the basic fundamentals of ethical policy-making and accountability to the public by not placing it under the Right To Information (RTI) act. This makes the decision non-transparent and reduces the trust of citizens in the government.

\subsection{Containment Policies and Decisions}

The Ministry of Health and Family Welfare (MHFW) implemented many measures through several frameworks to contain the spread of the COVID-19. The measures included geographic quarantine and cluster containment. That means the strategy was to restrict the movement of people from one place to another to avoid infections from COVID-19, especially movement from the COVID-19 affected area. Cluster containment means that the disease must be contained within a defined geographic area by adopting the approach of early detection of COVID-19 cases.

The cluster containment approach includes geographic quarantine of patients, social distancing of people, testing of all COVID-19 suspected cases, and awareness amongst the public about COVID-19. Additionally, the government placed several restrictions on the export of certain items, especially medical equipment and items used in medicare. This was done to ensure the availability of such equipment and items in the country. Such items included ventilators, beds, surgical masks for doctors, diagnostic kits for COVID-19, and medications such as paracetamol and hydroxychloroquine. But India's population is huge and this measure did not have a substantial impact on the COVID-19. Local manufacturing of health equipment was not as fast as required. Quality has also been an issue as the testing kit accuracy has been questionable due to the very low level of accuracy. Health system issues and the accuracy in testing have also been issues. For instance, there have been many instances in which one person has been declared COVID-19 positive at one place and the same person declared COVID-19 negative in another place. This created huge confusion in terms of efficacy and containment strategies.

\subsection{Migrant Crisis}

Due to the various decisions and policy measures taken, humanitarian crises erupted due to the huge crowds gathering at railway stations and bus stops in different states. This whole unexpected flood of immigrants defeated the purpose of the lockdown and social distancing. Migrants had the psychological fear that the only safe place was their native village. Even the assurances given by political leaders were not convincing and assuring, taking into account the preparedness of the government. Food and shelter were arranged due to public outrage. Such a scene shows that the decision was not considered thoroughly. Decision and policy lacked the care-of-ethics approach and was against human rights and ethics of care. Such a large section of the society depends on daily wages and are hand-to-mouth labourers. Such a sudden lockdown, although made with good intentions, therefore did not take their needs into consideration. Some of these migrants committed suicide or created law-and-order situations. In response, the police authorities used many inhumane and unethical 
measures of suppression and brutality against the migrants despite their just demands of reaching their home in distant villages and towns. The government only made appeals to the private sector and employees not to be fired but shop owners and private businesspeople think too much about profits and hence they did not pay much attention to the appeal. They were also not satisfied with the government. Some economists claimed that authorities provided relief in the form of a loan, not the stimulus. Some state governments were so short of funds that they had to open the liquor shops without social distancing and masking, which again spread the virus and defeated the lockdown. Such steps created an impression that the life of the migrants and low-wage employees is ethically not important in the economy of the country. Social organisations and religious groups belonging to all communities and places such as Temples, Masjids, Gurudwaras, and so on came forward and provided food and shelter by running community kitchens. The government preparations and execution of action and policy decisions to contain COVID-19, were not highly appreciated in terms of their execution and outcomes.

\subsection{Lockdown and Its After-Effects}

Lockdown, which was claimed to save people from the community transmission of the COVID-19 virus, failed miserably and caused irreparable damage to the life and economy of India, leading it to a spiral recession. At that time, India's COVID-19 numbers were the third highest all over the world. The United States was in the top position, followed by Brazil. Taking the COVID deaths per million population in India called the Crude Mortality Rate, India has done very poorly in comparison to nearby China, Indonesia, Sri Lanka, Nepal, Bangladesh, and Malaysia. India has also not fared as well as the African countries. There is no doubt that the lockdown was needed. But the manner in which it was imposed, it needed a carefully targeted and curated strategy regionally. Since the government followed the uniform lockdown policy in the whole country, this resulted in a double shock for the socio-economic state of the country. India's economy has spiralled down from its high growth rate and the pandemic has been spiralling up. resulting in the failure of the uniform lockdown policy. The COVID-19 infection rates have picked up and are increasing at an alarming rate. At the time of announcement of lock down, there was a natural expectation among the indian citizens that the Government and its administration had a strategy and workable contingency plans to handle the reduction in economic activities and work and the movement of people and goods from one part of country to another. But after careful observation, it has been quite visible that the people's expectations did not meet. Confusion and lack of preparedness was evidently visible in policy and action programmes. Let's take one country example of the least developed continent, Africa. The South African government also imposed a severe lockdown. But after the announcement, the government took the initiative and started to step up the building of specialised COVID-19 hospital facilities and COVID-19 testing centres. This was lacking in India. In India, there were very few and insufficient government actions leaving the migrant workers on their own. The Economist magazine [35] (June 13, 2020) estimated that the Indian administration issued a list of rule and their changes leading to the count of 4,000. The lack of COVID-19 disease information and relevant education and awareness and the frequent changing of rules created confusion [34]. This is against the fundamentals of ethical governance and policy making. Later on, the lockdown itself contributed to the COVID-19 spread due to people huddling together, infecting one another and causing people to travel hundreds of miles.

\subsection{Biased Role of Media}

All over the world due to technological advancements and globalization, digital news consumption and dissemination have become very fast. It has become instant with notification of our choices available to us through several platforms and social media networks. The media is responsible for framing the opinion and excessively developing the perception. To the highest degree, it goes on to create panic, depending on the coverage, as happened in the case of COVID-19 in India. At present, fake news is also a global phenomenon that governments and other stakeholders try to use for their purpose. Several fake news stories and manipulation of data have 
been identified. The lack of digital literacy and the habit of traditional belief have made fake news more prevalent. TV news channels have manipulated the content in order to suit their ideological affiliations and favouring the government at the states and centre. Celebrities without any specialized domain knowledge and scientific understanding propagated unscientific opinions and personal beliefs among their followers which reduces the accountability to the government officials. Due to the mandatory containment of the population in their respective houses, online media consumption has reached an all-time high, which has also led to health anxiety, somatic complaints, anxiety, depressive disorders, agitation, and insomnia. There have been so many high-profile deaths due to depression and to not being able to access the medication and help of loved ones. During the lockdown and the containment policies and decisions, it has been observed that social media has played a very critical role and an unethical role in marginalized and vulnerable sections of society. For instance, Muslims have been targeted, immigrant minors have been beaten, and so on. People from the Northeast, certain religious communities, and lower socio-economic classes like the migrants and homeless have already been victims of such stigmatization. The government also did not seem very active in containing and directing the social media platforms to make them ethical and rational in content dissemination and blocking the miscreant elements proactively. Claims related to the vaccine have also been very dubious and increases the people's anxiety and insecurities. Government decisions and policies have been seen as unethical and they seem to provide the benefits without the need of critical assessment and ethical scrutiny of claims on a scientific basis.

\section{CONCLUSION}

COVID-19 has impacted many countries severely in terms of losses of lives, socio-economic problems, heath and infrastructure emergencies, surging unemployment. and hardships for several sections of societies. People have also suffered from anxiety, lack of motivation, and psychological fears and traumas. Some countries have faced the situation well and some have suffered badly. Both types of countries approach the needs analysis of their actions and policies, critically and from ethical perspectives as well. In this light, there is a need to analyse the way India, a very diverse country in South Asia, has taken COVID-19 containment measures and what were their outcomes and impacts on society? These measures in terms of the policy, decision, and execution need ethical assessment so that they can become a guiding light for governance if such challenging times come in the future. The present study has highlighted the problems and issues that emerged due to the implementation and execution of the Indian administration approach, which consisted of unplanned lockdown and its exit strategy; the collapse of economic activity; and its impact on socio-economic systems and citizens, immigrant issues, and the lack of ethics-of-care and human rights violations in execution. Indian government decisions have been found lacking the ethics-of-care approach, as was evident in the circulation of misinformation on public spaces, targeting the social communities, lack of strong directives from government officials for the termination of jobs of employees by private companies, problems faced by healthcare professions. The suggestion and discussion provide lessons for future preparations for any pandemic.

\section{CONFLICT OF INTEREST}

The author confirms that there is no conflict of interest with this work.

\section{REFERENCES}

[1] 2020. Pradhan mantri garib kalyan yojana: All you need to know. The Times of India.

[2] 2020. We have prepared India for the worst: Health minister on Covid crisis. The Economic Times.

[3] Accessed on 21 Sep, 2021. Covid19 India website. (Accessed on 21 Sep, 2021).

[4] Thamina Acter, Nizam Uddin, Jagotamoy Das, Afroza Akhter, Tasrina Rabia Choudhury, and Sunghwan Kim. 2020. Evolution of severe acute respiratory syndrome Coronavirus 2 (SARS-CoV-2) as Coronavirus disease 2019 (COVID-19) pandemic: A global health emergency. Science of the Total Environment (2020), 138996.

[5] Editorial Article. 2020. Coronavirus in India highlights: Ventilators, masks, PPEs, tests kits exempted from customs duty. The Business Today (2020). 
[6] Prashasti Awasthi. 2020. Centre invokes "E pidemic Act" and "D isaster Management Act" to prevent spread of Coronavirus. The Hindu Business Line.

[7] Suborna Barua et al. 2020. Understanding coronanomics: The economic implications of the Coronavirus (COVID-19) pandemic. SSRN Electronic fournal https://doiorg/10/ggq92n.

[8] Samiksha Pandekar Bharat Vasani. 2020. Is the central government Coronavirus lockdown order constitutionally valid? The Bloom Berg Quint (2020).

[9] Soutik Biswas. 2020. Coronavirus: India's pandemic lockdown turns into a human tragedy. BBC.

[10] Chetan Chauhan. 2020. COVID-19| 52 labs for Coronavirus test for 1.3 billion people: An appraisal. Hindustan Times.

[11] Daisy Cheung and Eric C. Ip. 2020. COVID-19 lockdowns: A public mental health ethics perspective. Asian Bioethics Review 12, 4 (2020), 503-510.

[12] Nistula Hebbar. 2020. PM Modi announces 21-day lockdown as COVID-19 toll touches 12. The Hindu.

[13] Dineshani Hettiarachchi, Nafeesa Noordeen, Chanpika Gamakaranage, E. A. Rumesh Buddhika D. Somarathne, and Saroj Jayasinghe. 2020. Ethical responses to the COVID-19 pandemic-lessons from Sri Lanka. Asian Bioethics Review (2020), 1-9.

[14] Toby S. James and Sead Alihodzic. 2020. When is it democratic to postpone an election? Elections during natural disasters, COVID-19, and emergency situations. Election Law fournal: Rules, Politics, and Policy 19, 3 (2020), 344-362.

[15] Sajai Jose. 2020. Five COVID-19 policy mistakes India could have done without. The Wire.

[16] Pawanjot Kaur Kabir Agarwal. 2020. ICMR removes COVID-19 test price cap but private labs call government's bluff. The Wire (2020).

[17] Abhay B. Kadam and Sachin R. Atre. 2020. Negative impact of social media panic during the COVID-19 outbreak in India. Journal of Travel Medicine 27, 3 (2020), taaa057.

[18] Veria Khosrawipour, Hien Lau, Tanja Khosrawipour, Piotr Kocbach, Hirohito Ichii, Jacek Bania, and Agata Mikolajczyk. 2020. Failure in initial stage containment of global COVID-19 epicenters. fournal of Medical Virology 92, 7 (2020), 863-867.

[19] Soumyadeep Mukherjee. 2020. Disparities, desperation, and divisiveness: Coping with COVID-19 in India. Psychological Trauma: Theory, Research, Practice, and Policy 12, 6 (2020), 582.

[20] Ajeet mahale Omar Rashid, Jatin Anand. 2020. India Coronavirus lockdown | Migrant workers and their long march to uncertainty. The Hindu.

[21] PTI. 2020. Coronavirus outbreak: Rajasthan stops using China-made rapid testing kits; only 5.4 percent results accurate, says state health minister. The First Post.

[22] PTI. 2020. Domestic flights suspended from Tuesday midnight to 31 March. The Print.

[23] Debraj Ray and S. Subramanian. 2020. India's Lockdown: An Interim Report. Technical Report. National Bureau of Economic Research.

[24] Samuel Asumadu Sarkodie and Phebe Asantewaa Owusu. 2020. Impact of meteorological factors on COVID-19 pandemic: Evidence from top 20 countries with confirmed cases. Environmental Research 191 (2020), 110101.

[25] Sohini Sengupta and Manish K. Jha. 2020. Social policy, COVID-19 and impoverished migrants: Challenges and prospects in locked down India. The International fournal of Community and Social Development 2, 2 (2020), 152-172.

[26] Bindu Shajan. 2020. Coronavirus | Longer lockdown essential to break chain of infection, says government. The Hindu.

[27] Ram Singh. 2020. View: Govt's relief measures will help those worst affected by the lockdown, but will it do the trick? The Economic Times (2020)

[28] Shiva Sahay Singh. 2020. NICED admits testing kits have problem in West Bengal. The Hindu.

[29] Viroj Tangcharoensathien, Neville Calleja, Tim Nguyen, Tina Purnat, Marcelo D’Agostino, Sebastian Garcia-Saiso, Mark Landry, Arash Rashidian, Clayton Hamilton, Abdelhalim AbdAllah, et al. 2020. Framework for managing the COVID-19 infodemic: Methods and results of an online, crowdsourced WHO technical consultation. fournal of Medical Internet Research 22, 6 (2020), e19659.

[30] Kiran Tare. 2020. NIV Pune-the backbone of Covid testing in India | India Today Insight. India Today.

[31] K. Venkatramananan. 2019. Explained: India's asymmetric federalism. The Hindu.

[32] Patrick G. T. Walker, Charles Whittaker, Oliver J. Watson, Marc Baguelin, Peter Winskill, Arran Hamlet, Bimandra A. Djafaara, Zulma Cucunubá, Daniela Olivera Mesa, Will Green, et al. 2020. The impact of COVID-19 and strategies for mitigation and suppression in low-and middle-income countries. Science 369, 6502 (2020), 413-422.

[33] Bo Yan, Xiaomin Zhang, Long Wu, Heng Zhu, and Bin Chen. 2020. Why do countries respond differently to COVID-19? A comparative study of Sweden, China, France, and Japan. The American Review of Public Administration 50, 6-7 (2020), 762-769.

[34] India's bureaucrats are fighting covid-19 with red tape. 2020. The Economist. Retrieved on 13 Jan, 2021 from https://www.economist. com/asia/2020/06/11/indias-bureaucrats-are-fighting-covid-19-with-red-tape.

[35] The Economist magazine (June 13, 2020) estimated that the Indian administration issued a large set of rule to be followed by public to curb COVID-19 and its associated situations. The rules count was approaximatley 4,000. Retrieved from https://www.economist.com/ asia/2020/06/11/indias-bureaucrats-are-fighting-covid-19-with-red-tape.

Received May 2021; revised September 2021; accepted November 2021 